\title{
A COMPARATIVE STUDY OF TREATING MIDCLAVICULAR FRACTURES WITH PLATING AND TENS NAILING- A CASE SERIES
}

\author{
1 Professor, Department of Orthopaedics, Chengalpattu Medical College Hospital. \\ ${ }^{2}$ Assistant Professor, Department of Orthopaedics, Chengalpattu Medical College Hospital. \\ ${ }^{3}$ Assistant Professor, Department of Orthopaedics, Chengalpattu Medical College Hospital. \\ ${ }^{4}$ Assistant Professor, Department of Orthopaedics, Chengalpattu Medical College Hospital.
}

Murugasarathy Sambandam¹, Kalaiyarasan Thamizharasan², Duraisamy Ezhilmaran 3 , Maharajothi Paramasivam ${ }^{4}$

ABSTRACT

\section{BACKGROUND}

Middle third clavicle fractures are one of the most common types of fractures, especially in young adults. But management part is still under debate. In olden days, most of the fractures managed by conservative methods by arm sling and figure-of-eight bandage. Plating remains the standard procedure for fixation, an attracting alternative method of fixation is the Titanium Elastic Nailing (TENS). However, prospective randomised studies comparing the two methods of fixation are very minimal.

\section{MATERIALS AND METHODS}

40 unilateral displaced midclavicular fractures operated between August 2015 and December 2016 were included in the study. All the cases were operated and followed up every two weeks postoperatively. Functional outcome and union was analysed on followup.

\section{RESULTS}

During analysis, we had 20 patients in the plate group and 20 patients in the TEN group. There was faster union, lesser operative time, lesser blood loss with minimal complications were noted in the TEN group.

\section{CONCLUSION}

The use of minimally invasive antegrade TEN for fixation of displaced midshaft clavicle fractures is recommended.

\section{KEYWORDS}

Clavicle Fractures, Internal Fixation of Clavicle Fractures, Plate, Titanium Elastic Nailing.

HOW TO CITE THIS ARTICLE: Sambandam M, Thamizharasan K, Ezhilmaran D, et al. A comparative study of treating midclavicular fractures with plating and TENS nailing- a case series. J. Evolution Med. Dent. Sci. 2017;6(31):2577-2580, DOI: $10.14260 /$ Jemds/2017/557

\section{BACKGROUND}

Middle third clavicle fractures are one of the most common types of fractures with incidence of $2.6-10 \% .{ }^{[1]}$ But management part is still under debate. In olden days, most of the fractures managed by conservative methods by arm sling and figure-of-eight bandage.[2,3,4] But due to increasing demands and early mobilisation of patients, nowadays these fractures are managed by Open Reduction and Internal Fixation with plates and screws and Closed Reduction and Internal Fixation with Titanium Elastic Nailing System (TENS).[5]

\section{Aim of the Study}

This series aim to study and compare the functional outcome of midshaft clavicle fractures managed by ORIF with plating and CRIF/ORIF with TENS.

Financial or Other, Competing Interest: None.

Submission 06-03-2017, Peer Review 06-04-2017,

Acceptance 12-04-2017, Published 17-04-2017.

Corresponding Author:

Dr. Murugasarathy Sambandam,

Department of Orthopaedics,

Chengalpattu Medical College Hospital,

Chengalpattu, Kanchipuram,

Tamilnadu.

E-mail: s.murugasarathy@gmail.com artsking2003@gmail.com

DOI: $10.14260 /$ jemds $/ 2017 / 557$

\section{(c) $($ ) $\$$}

\section{MATERIALS AND METHODS}

This is a prospective study of 40 cases of midshaft clavicular fractures treated by ORIF with plating and CRIF/ORIF with TENS nailing. Patients were explained about the procedures, complications and postoperative protocols. Informed consent has been obtained from all patients.

The period of study and followup extends from August 2015 to December 2016 in the Department of Orthopaedics, Chengalpattu Medical College Hospital.

Out of 40 cases randomised by pre-randomisation method 20 cases selected for ORIF with Plating and 20 cases selected for CRIF/ORIF with Elastic Nailing.

\section{Surgical Methods and Post-Operative Protocol}

All patients were received in emergency OPD; after initial stabilisation patients were clinically evaluated for lifethreatening injuries. After ruling out life-threatening injuries patient initially immobilised with strapping, cuff and collar and clavicle brace and then patient shifted to our ward. Planning of surgical management based on x-ray findings, patient demand, displacement, type of fracture and associated injuries. Based on this, our study had 2 groups of 20 patients managed by ORIF with plating and CRIF/ORIF with TENS nailing. Most of the cases were operated within $3^{\text {rd }}-5^{\text {th }}$ day of admission.

The inclusion criteria were diaphyseal, non-comminuted midshaft clavicle fractures with more than $20 \mathrm{~mm}$ shortening/displacement in any view. 
Exclusion criteria were patients with proximal or distal fractures, floating shoulder, compound injuries, brachial plexus injury, comminuted fractures and associated with other injuries.

\section{Operative Procedure of ORIF with Plating}

All patients were informed about the procedure, complications and postoperative protocols and informed consent obtained from the patients. Under GA/Local nerve block patient in supine posture with sandbag in interscapular region, parts are painted and draped. Fracture fragments were fixed with 3.5 $\mathrm{mm}$ low profile reconstruction plate/anatomical locking compression plate on superior or anterior surface of clavicle. Patient immobilised with arm sling, suture removal done on $12^{\text {th }}$ day, arm sling discontinued and pendulum exercises started with restriction for hard work. Patients reviewed every 2 weeks and assessed for union with radiograph till union. When radiograph showed signs of union, patient was allowed for active and passive exercises. In our study, all the 20 cases had good radiological union in anatomical position by 12 to 16 weeks. We had complication of infection in 2 patients, but fracture gets united and removed the plate by $20^{\text {th }}$ week which settled later.

\section{Operative Procedure of CRIF/ORIF with Tens}

All patients operated under GA/regional block, patient positioned in a radiolucent table. In Beach Chair position with sandbag in the interscapular region, parts were painted and draped. About 1 to $2 \mathrm{~cm}$ incision was made in the medial end of clavicle, $1.5 \mathrm{~cm}$ from the sternoclavicular joint; with the help of $2.5 \mathrm{~mm}$ drill bit a small window was created in the anterior wall of clavicle. The window was widened with the help of small bone awl. Then elastic nail size of 2 or $2.5 \mathrm{~mm}$ size was introduced with a T-handle; with gentle oscillating movements, the nail was advanced up to the fracture site. With the help of image intensifier nail passed into the lateral segment, if closed reduction was found to be unsuccessful a small incision was made at the fracture level to negotiate the fragments. The nail was advanced into the lateral segment and nail was cut off at the site of insertion leaving $1 \mathrm{~cm}$ length for easy removal. Skin was closed without drain and sterile dressing applied.

In the postoperative period, the arm rested in an arm sling. On the third postoperative day, patient was discharged from the wards and gentle pendulum exercises started. On $12^{\text {th }}$ postoperative day, sutures were removed and patient was advised to start active mobilisation exercises. At 6 weeks, check x-ray taken to evaluate bony union. In our study, all the 20 cases had good radiological union by the end of 8 to 10 weeks.
Implant exit was done after radiological evidence of union. Of the 20 cases operated, nail was removed in 12 cases. Nail removal was done under local anaesthesia as an outpatient procedure.

\section{RESULTS}

Out of 40 patients, 20 were operated with plating and 20 with tens nail, males are predominant. Among 20 cases operated with ORIF with plating, 15 patients got union in 12 weeks, 5 got union in 16 weeks. Out of 20 patients 10 had excellent outcome, 6 had good outcome, 4 had moderate outcome; 2 cases got superficial infection. Clinical and radiological evidence of union was noted. Implant exit was done after 20 weeks, infection settled down after removal of implant.

Among 20 cases operated with elastic nailing, 18 patients has got union in 12 weeks, 2 got union by 16 weeks. Out of 20 , 16 had excellent outcome, 3 had good outcome, 1 had moderate outcome. Implant exit done for 12 cases after confirming clinical and radiological evidence of union.

There was no significant difference between the two groups with respect to age $(\mathrm{P}=0.92)$, sex $(\mathrm{P}=0.41)$ and trauma to surgery delay $(\mathrm{P}=0.5)$.

\begin{tabular}{|c|c|c|}
\hline Results & Plating (20) & Elastic Nail (20) \\
\hline \multicolumn{3}{|l|}{ Gender } \\
\hline Male & 16 & 14 \\
\hline Female & 4 & 6 \\
\hline \multicolumn{3}{|l|}{ Side } \\
\hline Right & 8 & 7 \\
\hline Left & 12 & 13 \\
\hline \multicolumn{3}{|l|}{ Type of Injury } \\
\hline RTA & 15 & 13 \\
\hline Assault & 1 & 1 \\
\hline Fall & 4 & 6 \\
\hline \multicolumn{3}{|l|}{ Timing of Surgery } \\
\hline$<3$ & 6 & 6 \\
\hline $3-5$ & 11 & 12 \\
\hline$>5$ & 4 & 2 \\
\hline $\begin{array}{l}\text { Union in Anatomical } \\
\text { Position }\end{array}$ & 20 & 20 \\
\hline Union in 12 Weeks & 15 & 18 \\
\hline Union in 16 Weeks & 5 & 2 \\
\hline Nonunion & Nil & Nil \\
\hline Malunion & Nil & Nil \\
\hline $\begin{array}{l}\text { Early Return } \\
\text { to Activity }\end{array}$ & $\begin{array}{c}28 \text { Days } \\
\text { (16 Cases) }\end{array}$ & $\begin{array}{c}\text { 14 Days } \\
\text { (18 Cases) }\end{array}$ \\
\hline \multicolumn{3}{|c|}{ Table 1. Results } \\
\hline
\end{tabular}

\begin{tabular}{|c|c|c|}
\hline Description & Plating (20) & Elastic Nail (20) \\
\hline Stiffness of shoulder & 3 & Nil \\
\hline $\begin{array}{c}\text { Loss of length of clavicle } \\
\text { (shortening }>\text { 2 cms) }\end{array}$ & Nil & $\begin{array}{c}\text { Excellent- 16 Cases } \\
\text { Good- 3 Cases } \\
\text { Moderate- 1 Case } \\
\text { Poor- Nil }\end{array}$ \\
\hline $\begin{array}{c}\text { Patient Compliance and } \\
\text { Functional Outcome }\end{array}$ & $\begin{array}{c}\text { Excellent- 10 Cases } \\
\text { Good- 6 Cases } \\
\text { Moderate- 4 Cases } \\
\text { Poor- Nil }\end{array}$ & $\begin{array}{c}\text { Nail migration- 1 Case } \\
\text { Skin irritation- 2 Cases } \\
\text { Infection- Nil }\end{array}$ \\
\hline Other Complications & $\begin{array}{c}\text { Infection- 2 Cases } \\
\text { Stiffness of Shoulder- 3 Cases } \\
\text { Hypertrophied Scar- 3 Cases }\end{array}$ \\
\hline
\end{tabular}




\begin{tabular}{|c|c|c|}
\hline Test & $\begin{array}{c}\text { Clinical Union } \\
\text { in Weeks }\end{array}$ & $\begin{array}{c}\text { Radiological } \\
\text { Union in Weeks }\end{array}$ \\
\hline Mann-Whitney U & 32.000 & 32.000 \\
\hline Wilcoxon W & 152.000 & 152.000 \\
\hline Z & -3.433 & -3.426 \\
\hline Asymp. Sig (2-tailed) & .001 & .001 \\
\hline $\begin{array}{c}\text { Exact Sig [2*(1-tailed } \\
\text { sig.) }]\end{array}$ & $.000^{\mathrm{a}}$ & $.000^{\mathrm{a}}$ \\
\hline \multicolumn{2}{|c|}{ Table 3. Test Statistics } \\
\hline
\end{tabular}

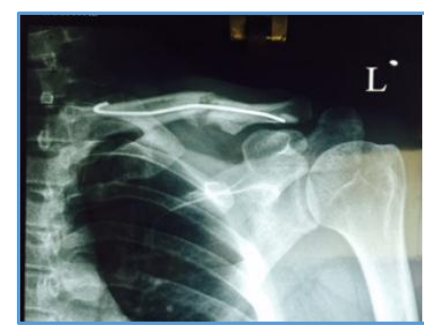

Immediate Post-Op

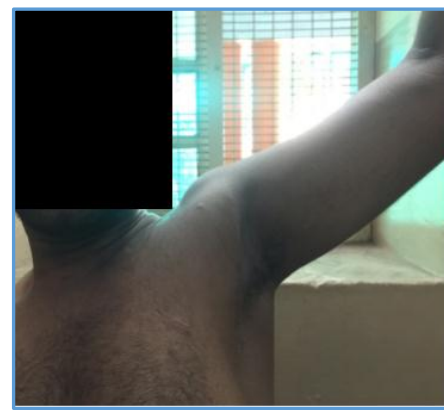

Clinical Photo- 1

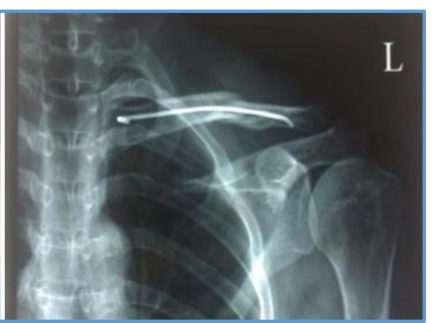

Follow-Up

a. Not corrected for ties

b. Grouping variable: group

\section{Case Illustration}

Case I (ORIF with Plating)

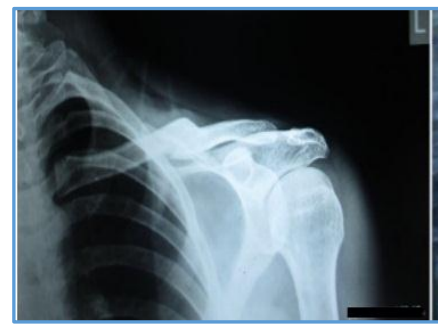

Pre-Op

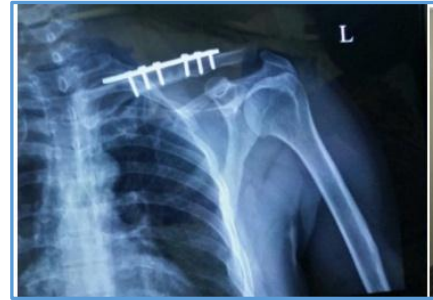

Follow-Up

Case- II (CRIF with Nailing)

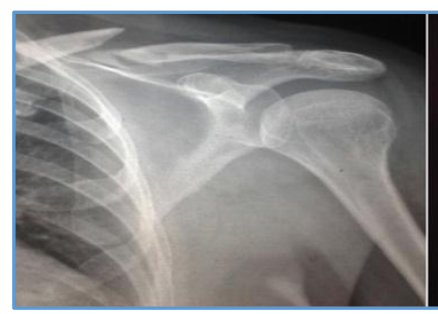

Pre-Op

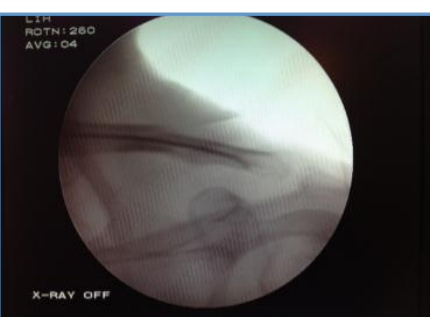

C-Arm Picture- 2

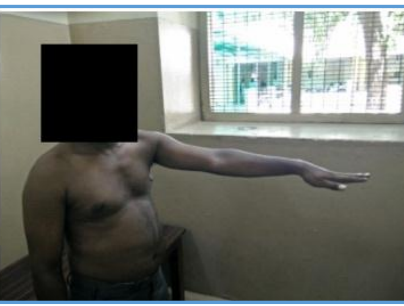

Clinical Photo- 1
Immediate Post-Op

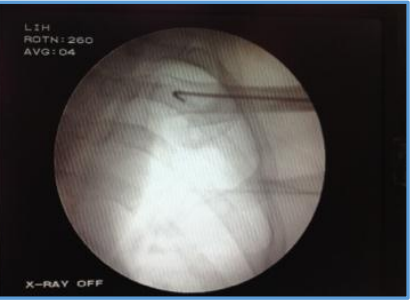

C-Arm Picture- 1

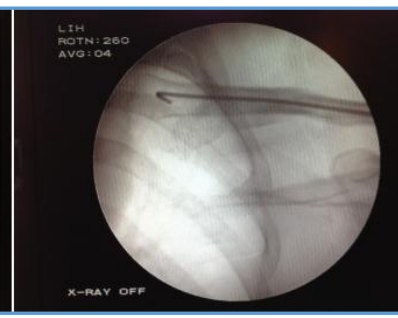

C-Arm Picture- 3

\section{DISCUSSION}

Clavicle fractures are one of the most common fractures of young active individuals. Most of the clavicle fractures were managed by conservative method previously, but after understanding the fracture biomechanics of clavicle surgical management was found to have good functional outcome and early mobilisation of patients. Fracture patterns like displaced, comminuted, shortening $>2 \mathrm{~cm}$ all have impact on union and functional outcome.

Intramedullary nailing for clavicle fractures is an alternative and less invasive way of fixation, which is better in the biomechanical point of view as the tension side of clavicle changes with respect to rotation of arm and direction of loading.[5,6] The advantage of intramedullary stabilisation include smaller incision, minimal periosteal stripping, load sharing device properties[7] and its complication includes skin irritation, cannot be used in comminuted fracture because this system can lead to telescoping and cannot maintain length.

Duan et al[8] in a meta-analysis of randomised controlled trials demonstrated similar functional outcome when comparing plating with intramedullary fixation. They, however, showed higher symptomatic hardware-related problems with plating. Zlowodzki et al[9] in a systematic review of 2144 cases found non-union rate of $1.6 \%$ with intramedullary fixation as compared with $2.5 \%$ with plate fixation.

The intramedullary fixation provides an alternative and less invasive way of surgically treating clavicle fractures. The use of titanium elastic nails in the treatment of midshaft clavicle fractures was first described by Jubel et al[10] and Chen et al[11] in a comparative study between tens nail and plating. TENS group showed shorter time to union with the TENS group, with better functional outcome and faster recovery. Migration of intramedullary implant has been reported in a number of studies.

In our study 20 patients were treated with ORIF with plating, another 20 patients were treated with CRIF/ORIF with elastic nailing. 
Though each procedure having advantages and disadvantages, the functional outcome of surgical methods was found to be better when compared to conservative methods. Elastic nailing was not indicated for comminuted fractures and fracture non-union. The advantage of intramedullary fixation and not disturbing the fracture haematoma are additive features of closed nailing.

In our study, functional outcome in terms of early mobilisation, clinical union and radiological union was found to be significant with p-value of (.000), (.001) and (.001) respectively (all values were less than $<0.05$ ). Hence, patients were treated with elastic nailing had good functional outcome, faster recovery and good anatomical reduction.

Previous literatures and studies compared the functional outcome of conservative methods and plating, conservative methods and nailing. But only small numbers of studies were comparing plating versus nailing. Our study compared the functional outcome of plating versus nailing.

\begin{tabular}{|c|c|c|c|c|c|c|}
\hline \multirow[b]{2}{*}{ Results } & \multicolumn{2}{|c|}{$\begin{array}{c}\text { Smekal et al (2009) } \\
60 \text { Cases }\end{array}$} & \multicolumn{2}{|c|}{$\begin{array}{c}\text { Chen QY et al [2011] } \\
60 \text { Cases }\end{array}$} & \multicolumn{2}{|c|}{$\begin{array}{l}\text { Our Study } \\
30 \text { Cases }\end{array}$} \\
\hline & $\begin{array}{l}\text { Non-Operative } \\
\text { Method }\end{array}$ & Elastic Nailing & Non-Operative Method & Elastic Nailing & Plating & $\begin{array}{c}\text { Elastic } \\
\text { Nailing }\end{array}$ \\
\hline Nonunion & 3 & 0 & 3 & 0 & 0 & 0 \\
\hline Malunion & 2 & 0 & 2 & 0 & 0 & 0 \\
\hline Infection & 0 & 0 & 0 & 0 & 2 & 0 \\
\hline Nail migration & - & - & - & 5 & - & 1 \\
\hline \multicolumn{7}{|c|}{ Table 4. Outcome Comparison } \\
\hline
\end{tabular}

Our study shows good functional outcome for Elastic Nailing when compared to Plating with significant value of $(\mathrm{P}<0.05)$.

\section{CONCLUSION}

Even though increased popularity of surgical methods, most of the clavicle fractures were managed by conservative methods till now. Nonsurgical methods are nowadays used in elderly patients with less physiological demand.

But increasing evidence of good functional outcome of surgical methods favours fixation for young individuals and elderly patients with physiological demand.

Good anatomical reduction for comminuted fractures and no need for implant exit are merits of plating. But surgical scar and chances of infection are more in plating.

Intramedullary fixation, minimally invasive and early mobilization are the merits of elastic nailing. But disadvantage includes need for implant exit, nail migration, limitation in comminuted fractures.

In our study, we found that titanium elastic nail has excellent functional outcome with faster recovery in displaced midshaft clavicle fractures.

\section{REFERENCES}

[1] O'Neill BJ, Hirpara KM, O'Briain D, et al. Clavicle fractures: a comparison of five classification systems and their relationship to treatment outcomes. Int Orthop 2011;35(6):909-14.

[2] Neer CS. Nonunion of the clavicle. J Am Med Assoc 1960;172:1006-11.

[3] Rowe CR. An atlas of anatomy and treatment of midclavicular fractures. Clin Orthop Relat Res 1968;58:29-42.
[4] Jeray KJ. Acute midshaft clavicular fracture. J Am Acad Orthop Surg 2007;15(4):239-48.

[5] Denard PJ, Koval KJ, Cantu RV, et al. Management of midshaft clavicle fractures in adults. Am J Orthop (Belle Mead NJ) 2005;34(11):527-36.

[6] Smekal V, Irenberger A, Struve P, et al. Elastic stable intramedullary nailing versus nonoperative treatment of displaced midshaft clavicular fractures-a randomized, controlled, clinical trial. J Orthop Trauma 2009;23(2):106-12.

[7] Mueller M, Rangger C, Striepens N, et al. Minimally invasive intramedullary nailing of midshaft clavicular fractures using titanium elastic nails. J Trauma. 2008;64(6):1528-34.

[8] Duan X, Zhong G, Cen S, et al. Plating versus intramedullary pin or conservative treatment for midshaft fracture of clavicle: a meta-analysis of randomized controlled trials. J Shoulder Elbow Surg 2011;20(6):1008-15.

[9] Zlowodzki M, Zelle BA, Cole PA, et al. Treatment of acute midshaft clavicle fractures: systematic review of 2144 fractures: on behalf of the Evidence-Based Orthopaedic Trauma Working Group. J Orthop Trauma 2005;19(7):504-7.

[10] Jubel A, Andemahr J, Bergmann H, et al. Elastic stable intramedullary nailing of midclavicular fractures in athletes. Br J Sports Med 2003;37(6):480-3.

[11] Chen YF, Wei HF, Zhang C, et al. Retrospective comparison of titanium elastic nail (TEN) and reconstruction plate repair of displaced midshaft clavicular fractures. J Shoulder Elbow Surg 2012;21(4):495-501. 